\title{
Pemicuan Sanitasi Total Berbasis Masyarakat (STBM) Pilar BABS di Kota Sibolga
}

\author{
Rapotan Hasibuan ${ }^{1}$, Susilawati ${ }^{1}$, Meutia Nanda ${ }^{1}$ \\ ${ }^{1}$ Fakultas Kesehatan Masyarakat, Universitas Islam Negeri Sumatera Utara, JI. IAIN No. 1 Medan \\ Kota Medan, 20235, Indonesia
}

Corresponding author: Rapotan Hasibuan, Fakultas Kesehatan Masyarakat, Universitas Islam Negeri Sumatera Utara, JI. IAIN No. 1 Medan. E-mail : rapotanhasibuan@uinsu.ac.id

Riwayat Artikel

Diterima: 2021-04-21

Disetujui: 2021-05-13

Dipublikasi: 2021-10-01

\section{Keywords}

Pemicuan, Sanitasi Total Berbasis Masyarakat, Buang Air Besar Sembarangan, Sibolga

\begin{abstract}
Cakupan sanitasi total di Kota Sibolga masih tergolong rendah. Pengabdian masyarakat ini bertujuan merekonstruksi pemahaman warga akan pilar buang air besar sembarangan (BABS) di Kelurahan Huta TongaTonga, Kecamatan Sibolga Utara. Kegiatan ini penting dilakukan sehubungan hasil observasi lingkungan dan wawancara pada warga dan petugas kesehatan di lapangan yang menyoroti pemahaman PHBS individu dan kondisi geografis daerah sebagai penghambat utama. Metode yang digunakan dalam sosialisasi ini adalah metode ceramah berupa penyuluhan, pengukuran volume tinja, penyusunan diagram alur kontaminasi oleh warga. Metode penyuluhan dilengkapi pembuatan pemetaan BABS, cara cuci tangan yang benar, dan diskusi tanya jawab dengan muatan elemen pemicuan. Output yang dihasilkan berupa peningkatan pemahaman mengenai pentingnya merubah perilaku $B A B$ sembarangan dan kesadaran akan potensi penyakit yang dapat ditimbulkannya. Selain itu, output juga terlihat dari kemampuan warga dalam menyusun diagram alur kontaminasi tinja. Tindak lanjut kegiatan ini adalah pihak Dinas Kesehatan, pihak Kecamatan, Puskesmas, dan Kepala Desa hendaknya melakukan monitoring dan evaluasi hasil pemicuan STBM sampai pada akhirnya Kelurahan Huta Tonga-Tonga benar-benar menjadi Desa Stop Buang air Sembarangan (SBS).
\end{abstract}

\section{PENDAHULUAN}

Sanitasi yang layak dan baik merupakan hal mutlak dibutuhkan setiap diri dalam pemenuhan kebutuhan keseharian, tetapi tidak setiap orang dapat menyediakan dan mengelola sanitasinya dengan baik (Peal et al., 2020; Qasim \& Chiang, 1994; World Health Organization, 1981). Kementerian Kesehatan melaporkan akses sanitasi Indonesia per November 2018 baru mencakup 73,9\%, artinya masih ada $26,1 \%$ setara dengan hampir 69,16 juta jiwa (dari 265 juta jiwa) belum memiliki akses sanitasi dan sekitar 9,36\% atau 24,8 juta jiwa diantaranya masih buang air besar sembarangan (BABS) (Kementerian Kesehatan, 2020). Padahal pada RPJMN 2020-2024 disebutkan target akses sanitasi rumah tangga dengan akses sanitasi layak dan aman sebesar 90\% layak (termasuk 20\% aman). Cakupan sanitasi di Provinsi Sumatera Utara sendiri baru mencapai $72 \%$.

Cakupan sanitasi total di Kota Sibolga Provinsi Sumatera Utara berada dalam posisi belum mencapai angka target nasional dengan capaian sebesar 88,32\% (BPS, 2019; Dinkes Provsu, 2021). Rilis laporan STBM-SMART yang digunakan sebagai alat 
memonitoring progress pilar 1 STBM di Kota Sibolga menunjukkan baru 9 dari 17 kelurahan yang melaksanakan STBM, 8 kelurahan lainnya belum dilakuan pemicuan dan belum satu pun kelurahan yang menjadi Desa SBS (Stop Buang air besar sembarangan). Di sisi lain, hasil wawancara dengan Kepala Seksi Kesehatan Lingkungan dan Kesehatan Kerja Dinas Kesehatan kota setempat disebutkan terdapat sejumlah faktor yang menghambat kesuksesan STBM di antaranya adalah karakteristik geografi daerah yang terdiri dari perbukitan hingga lautan dan pendidikan warga yang termasuk kategori rendah.

Percepatan peningkatan akses sanitasi oleh pemerintah dilakukan dengan pendekatan Sanitasi Total Berbasis Masyarakat (STBM) yang ditandai dengan dikeluarkannya Keputusan Menteri Kesehatan Nomor 852 pada tahun 2008 dan yang terbaru adalah Peraturan Menteri Kesehatan Republik Indonesia Nomor 3 tahun 2014 tentang STBM. Sampai saat ini, STBM satu-satunya pendekatan perubahan perilaku yang menyasar langsung ke tingkat rumah tangga yang terbukti mampu meningkatkan akses sanitasi dan perubahan perilaku higiene dengan cepat (Kementerian Kesehatan, 2020, 2018; Kementerian Kesehatan, 2020).

Strategi pendekatan STBM menganut metode Participatory Rural Appraisal (PRA) dengan pelaksanaan 5 (lima) pilar STBM, yaitu: tidak BAB sembarangan, mencuci tangan pakai sabun (CTPS), mengelola air minum dan makanan yang aman, mengelola sampah dengan benar, dan mengelola limbah cair rumah tangga dengan bersih dan aman (Kementerian Kesehatan, 2018; Rasako, 2018).

Pemicuan STBM merupakan hal penting dalam pemberdayaan kesehatan masyarakat. Kegiatan ini mengajak masyarakat untuk menganalisa kondisi sanitasi mereka melalui suatu proses pemicuan, sehingga masyarakat dapat berpikir dan mengambil tindakan untuk meninggalkan kebiasaan BABS. Sampai saat ini, terdapat 55\% desa/kelurahan yang sudah dipicu dari total 80.805 desa/kelurahan yang ada pada sistem M\&E STBM Kemenkes dan $46 \%$ di antaranya telah mencapai status SBS (Kementerian Kesehatan, 2020). Penelitian terdahulu membuktikan bahwa pemicuan STBM berkontribusi besar dalam pencapaian Universal Akses (UA) Sanitasi dan peningkatan pengetahuan, sikap, serta perilaku warga untuk Stop BABS, CTPS dan pemilikan jamban (Anggie, 2020; Gargita et al., 2020; Musfirah et al., 2020; Muslikah et al., 2014). Prinsip yang dianut dalam pemicuan STBM adalah tanpa subsidi, tidak menggurui, tidak memaksa (Apriatman, 2009). Konten yang digunakan menyinggung elemen rasa jijik, rasa sakit dan harga diri warga sehingga tersadar dan tergerak melakukan sanitasi secara total.

\section{METODE}

Kegiatan pengabdian dilakukan dengan metode ceramah yaitu penyuluhan dan pengukuran volume tinja, sementara output kegiatan dilakukan dengan mengukur keberhasilan warga dalam menyusun diagram alur kontaminasi. Metode penyuluhan tidak hanya dengan ceramah, tetapi menginstruksikan masyarakat dalam pembuatan pemetaan BABS, melakukan pelatihan cara cuci tangan yang baik dan benar, dan membuat diskusi sesi tanya jawab dengan muatan elemen pemicuan. Kegiatan dilakukan 30 Maret sampai dengan 01 April 2021 (3 hari) bertempat di halaman Gapura Kelurahan Huta Tonga-Tonga. Masyarakat yang berpartisipasi pada kegiatan sebanyak 48 orang.

Antusias peserta terlihat pada pertanyaan-pertanyaan yang diajukan peserta berkaitan materi yang disampaikan. Kerena tingkat pendidikan partisipan yang rendah, maka bahasa yang digunakan adalah bahasa sederhana dan kaku. Harapannya untuk keberlanjutan 
kegiatan ini memberikan dampak positif bagi warga agar membiasakan untuk menerapkan 5 pilar STBM, khususnya tidak melakukan BABS secara konsisten.

\section{HASIL DAN PEMBAHASAN}

Kegiatan pengabdian masyarakat berjalan lancar dengan melibatkan sebanyak 48 orang warga Kelurahan Huta Tonga-Tonga. Pada saat kegiatan penyuluhan dilaksanakan, warga yang hadir memperhatikan dan menyimak dengan baik seluruh materi dalam kegiatan penyuluhan.Kegiatan pemicuan dilakukan untuk mendorong perubahan individu maupun masyarakat warga dari perilaku hidup yang tidak sehat menjadi perilaku yang sehat. Pada saat pemicuan, proses yang dilakukan adalah menyentuh perasaan dan hati masyarakat. Pemicuan sendiri dilakukan dengan 3 tahapan, yaitu: tahap pra pemicuan, tahap proses pemicuan dan tahap pasca pemicuan (Kementerian Kesehatan, 2018).

Tahap pra pemicuan dimulai dari fasilitator dalam hal ini pihak dosen dan Sanitarian Dinas Kesehatan Kota Sibolga mempersiapkan diri dan perangkat yang dibutuhkan dimulai dari observasi kebiasaan PHBS masyarakat, koordinasi dengan aparat kelurahan setempat, pemilihan prioritas lokasi pemicuan, penyusunan jadwal pemicuan, menghubungi tokoh setempat, persiapan diri pemicu (fasilitator), persiapan bahan pemicuan dan memastikan teknis keberangkatan pembentukan tim pemicu. Output dalam tahapan pra pemicuan ini adalah diperolehnya komitmen dari semua stakehoders di kelurahan Huta Tonga-Tonga dan ditentukannya titik-titik pemicuan.
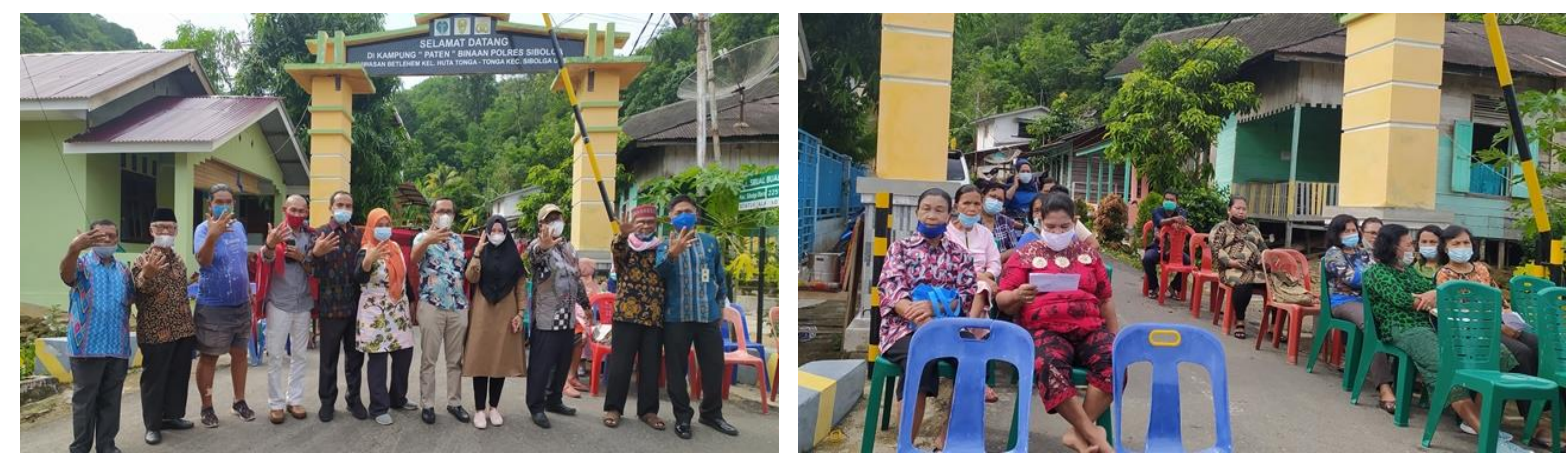

Gambar 1. Pihak Aparat Desa dan Masyarakat Terlibat Aktif dalam Kegiatan Sebagai Hasil Koordinasi Pra Pemicuan STBM

Komitmen dari stakeholder merupakan faktor penting dalam kesuksesan setiap program yang berhubungan dengan masyarakat, terutama berkaitan dengan kepentingan sanitasi. Pelibatan pihak yang berkepentingan terbukti mampu mendorong percepatan perwujudan program melalui pengintegrasian pembuatan keputusan bersama dan penyepakatan penanggungjawab bersama pencapaian program untuk setiap titik lokasi pemicuan (Zuin et al., 2019).

Stakeholder yang telah berkomitmen akan menggunakan posisinya untuk mengadvokasi upaya STBM dan meningkatkan sanitasi dengan membuka hubungan baik dengan banyak pemangku kepentingan lainnya. Sejalan dengan itu, stakeholder yang berasal dari lokal setempat terbukti lebih mudah membujuk masyarakat dibandingkan dengan fasilitator dari luar, seperti warga dari desa terdekat yang dapat membuktikan upaya STBM itu sangat mungkin terealisasi (Jiménez et al., 2014; Musyoki, 2016; Zuin et al., 2019). Setelah komitmen para pemangku kepentingan didapatkan, maka dilanjutkan dengan tahap proses pemicuan yang meliputi perkenalan, penyampaian maksud dan tujuan, bina 
suasana, identifikasi bahasa lokal untuk penyebutan BABS atau tinja, pemetaan titik BABS, hitung volume tinja, dan diskusi menggunakan elemen pemicuan.

Kegiatan pengenalan diri dan keakraban dengan masyarakat setempat dibutuhkan untuk menghilangkan "jarak" antara tim pemicu dan warga sehingga proses fasilitasi berjalan mulus. Selain itu, pencairan suasana dilakukan agar pesan pemicuan STBM dapat diterima dan tersampaikan pada setiap lapisan masyarakat yang berhadir. Sebagaimana studi Prayitno (2018) yang menemukan bahwa strategi bina suasana yang baik terbukti mendorong percepatan sosialisasi, koordinasi dan pelatihan yang berkitan dengan STBM pada salah satu kelurahan di Kota Surabaya (Iddrisu, 2016; Kementerian Kesehatan, 2018; Prayitno \& Widati, 2018).

Setelah proses perkenalan dan berhasil menemukan isitilah lokal dalam penyebutan BABS dan tinja, masyarakat diarahkan melakukan Pemetaan sendiri yang bertujuan untuk melihat peta buang air besar masyarakat dengan membuat garis-garis batas desa, jalanjalan utama desa, titik rumah. Sementara penghitungan volume tinja dilakukan agar masyarakat melihat kondisi dan menyadari banyaknya tinja yang diproduksi sehingga memicu rasa malu. Studi meyebutkan bahwa pemetaan area buang besar menjadi salah satu kegiatan yang paling berkesan dirasakan oleh Warga, seperti laporan studi di Mali yang mendapati pemetaan area buang air besar sembarangan menjadi aktivitas kedua yang paling diingat warga sebagai hasil pemicuan STBM (Alzua et al., 2015).
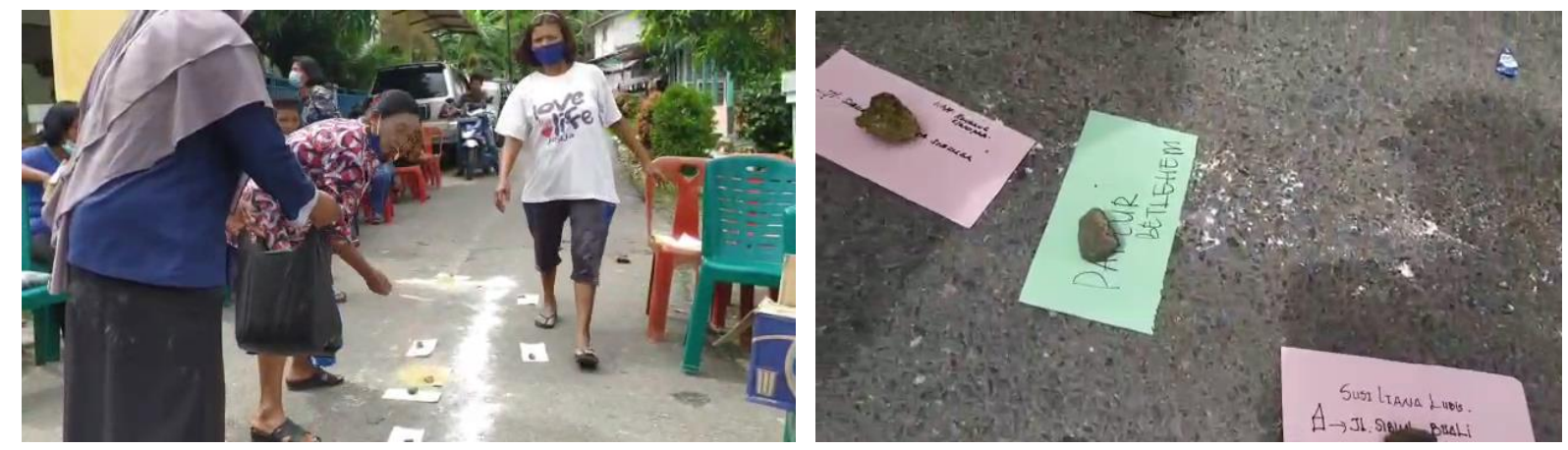

Gambar 2. Pemetaan Tempat Tinggal Warga dan Titik Lokasi Tempat BABS

Kegiatan pengabdian juga melakukan tindakan memahamkan masyarakat akan alur kontaminasi, yaitu mengajak masyarakat melihat bagaimana tinja manusia dapat dimakan oleh manusia lainnya. Kegiatan ini sekaligus menjadi indikator keberhasilan penyuluhan yang dilakukan. Hasilnya dari setiap warga yang ditunjuk untuk menyusun diagram alur, semuanya berhasil menyusun dengan tepat alur kontaminasi tinja, dan mampu menerangkan deskripsi setiap potongan alur yang ada. Kegiatan pengabdian berhasil membuat masyarakat mengerti asal muasal, alur proses hingga tinja terkonsumsi oleh manusia, dan terpicu rasa malunya untuk tidak buang air besar di sembarang lokasi. Hal ini dikarenakan seluruh tahapan pemicuan yang dilakukan selalu disertai diskusi yang bermuatan elemen pemicuan yaitu rasa jijik, rasa malu, takut sakit, rasa berdosa, kemiskinan dan aspek privasi warga.

Pendekatan STBM dengan elemen pemicuan sangat berbeda dengan pendekatan sanitasi masyarakat terdahulu yang menitikberatkan pada saran pembuatan fasilitas BABS berstandar baik, penyediaan insentif untuk memotivasi orang membangun toilet, dan penyediaan fasilitas toilet umum bersama di masyarakat. Pendekatan terdahulu tersebut tidak menjamin adopsi dan keberlanjutan praktik sanitasi yang baik (Kar, 2005). Faktanya, sebagian besar jamban bersubsidi banyak tidak digunakan atau justru digunakan untuk tujuan berbeda seperti pembuangan sampah, pemeliharaan ternak unggas, dan bahkan gudang penyimpanan barang (Sanan \& Moulik, 2007). 

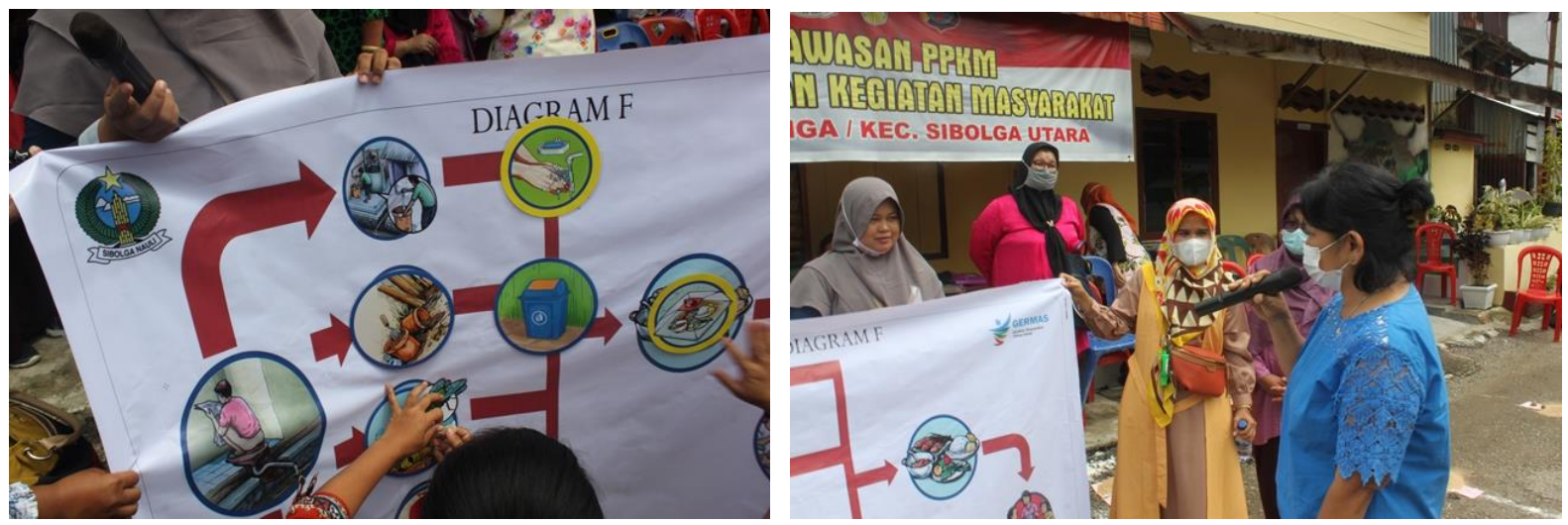

Gambar 3. Warga Menyusun Alur Kontaminasi Air dengan Bantuan Diagram Alur

Seluruh rangkaian kegiatan pengabdian pada akhirnya merekomendasikan kepada pihak Dinas Kesehatan, pihak Kecamatan, Puskesmas, dan Kepala Desa untuk memonitoring dan mengevaluasi hasil pemicuan sampai Kelurahan Huta Tonga-Tonga benar-benar menjadi Desa Stop Buang air Sembarangan (SBS). Disarankan pula bagi Stakeholder terkait untuk melakukan perluasan dusun dan kelurahan sekitarnya sehingga seluruh desa bisa menjadi desa SBS. Pihak Dinas Kesehatan hendaknya dapat memverifikasi Desa SBS yang lebih massif, melakukan deklarasi desa SBS, mendampingi desa pasca desa telah SBS dan mengembangkan media promosi untuk perubahan perilaku yang bekelanjutan. Musyoki (2016) menyebutkan bahwa antusiasme dan dukungan yang diperoleh dari masyarakat dalam mencapai Desa SBS perlu ditindaklanjuti dengan membangun dan menanamkan kerangka kelembagaan yang kuat, membangun kapasitas sumber daya manusia yang memadai, dan menyediakan semacam pembiayaan untuk memastikan keberlanjutan jangka panjang STBM (Musyoki, 2016).

\section{KESIMPULAN}

Kegiatan pemicuan STBM pada pilar BABS yang dilakukan di Kelurahan Huta TongaTonga Kecamatan Sibolga Utara Kota Sibolga menyimpulkan bahwa pemahaman dan kesadaran untuk tidak BABS sangat penting dan merupakan pilar utama dalam kesuksesan upaya STBM. Pada rangkaian kegiatan penyuluhan disampaikan materi dan pelatihan cuci tangan pakai sabun yang baik dan benar serta diskusi tanya jawab yang memuat elemen pemicuan. Secara umum, kegiatan berdampak kepada pemahaman warga yang dibuktikan dengan kemampuan warga menyusun diagram alur kontaminasi tinja, mampu menghitung volume tinja, dan dapat menjawab pertanyaan yang diberikan oleh pemateri ketika diskusi tanya jawab.

\section{UCAPAN TERIMA KASIH}

Ucapan terimakasih kepada Pimpinan Fakultas Kesehatan Masyarakat Prodi IImu Kesehatan Masyarakat Universitas Islam Negeri Sumatera Utara yang memberikan kesempatan penyelenggeraan kegiatan Pengabdian kepada Masyarakat pesisir di Kota Sibolga, dan seluruh dosen yang terlibat dalam tim pengabdian kesehatan masyarakat. Terimakasih juga disampaikan kepada pihak Dinas Kesehatan Kota Sibolga, khususnya Kepala Seksi Kesehatan Lingkungan dan Kesehatan Kerja yang turut langsung bersama tim memberikan arahan dan dukungan yang baik. 


\section{DAFTAR REFERENSI}

Alzua, M. L., Pickering, A. J., Djebbari, H., Lopez, C., Cardenas, J. C., Lopera, M. A., Osbert, N., \& Coulibaly, M. (2015). Impact evaluation of Community-Led Total Sanitation (CLTS) in rural Mali: Final report (Working Paper No. 191). Documento de Trabajo. https://www.econstor.eu/handle/10419/157941

Anggie, M. (2020). Pemberdayaan Masyarakat Oleh LAZ Harfa Melalui Program Pemicuan STBM Bidang Kesehatan (Studi Kasus di Desa Bojongmanik Kecamatan Sindangresmi Kabupaten Pandeglang) [Skripsi, UIN SMH BANTEN]. http://repository.uinbanten.ac.id/4954/

Apriatman, N. (2009). Stop Buang Air Besar Sembarangan: Pembelajaran dari Para Penggiat Community-Led Total Sanitation CLTS. Kelompok Kerja Air Minum dan Penyehatan Lingkungan (Pokja AMPL) bekerjasama dengan WASPOLA Facility. https://www.academia.edu/3098795/Stop_Buang_Air_Besar_Sembarangan_Commu nity_Led_Total_Sanitation_CLTS_Pembelajaran_dari_Para_Penggiat_CLTS

BPS. (2019). Badan Pusat Statistik Provinsi Sumatera Utara. https://sumut.bps.go.id/statictable/2019/11/20/1416/persentase-rumah-tangga-yangmemiliki-akses-terhadap-sanitasi-layak-menurut-kabupaten-kota-di-provinsisumatera-utara-2014---2018.html

Dinkes Provsu. (2021). Laporan STBM-SMART. Dinas Kesehatan Provinsi Sumatera Utara.

Gargita, I. W., Miswan, M., \& Rosnawati, R. (2020). Faktor-Faktor yang Mempengaruhi Kepemilikan Jamban Setelah Pemicuan STBM Di Desa Pantolobete Wilayah Kerja Puskesmas Lalundu Despot Kecamatan Rio Pakava Kabupaten Donggala. Jurnal Kolaboratif Sains, 1(1), Article 1. https://doi.org/10.31934/jom.v1i1.1180

Iddrisu, F. (2016). Socio-Demographic And Economic Factors That Influence Open Defecation In Lawra And Nandom Districts In The Upper West Region Of Ghana [Thesis, University for Development Studies]. http://udsspace.uds.edu.gh:80/handle/123456789/2000

Jiménez, A., Mtango, F. F., \& Cairncross, S. (2014). What role for local government in sanitation promotion? Lessons from Tanzania. Water Policy, 16(6), 1104-1120. https://doi.org/10.2166/wp.2014.203

Kar, K. (2005). Practical Guide to Triggering Community-Led Total Sanitation (CLTS). Institute of Development Studies. https://opendocs.ids.ac.uk/opendocs/handle/20.500.12413/2353

Kementerian Kesehatan. (2018). Modul Pelatihan Fasilitator Sanitasi Total Berbasis Masyarakat STBM-Stunting. Direktorat Jenderal Kesehatan Masyarakat: Kementerian Kesehatan RI. http://siakpel.bppsdmk.kemkes.go.id:8102/akreditasi_kurikulum/modul_21012510461 96d3ab791b8fac2d52467d335a9683ace

Kementerian Kesehatan. (2018). Riset Kesehatan Dasar (Riskesdas) 2018. Kementerian Kesehatan Republik Indonesia. https://www.litbang.kemkes.go.id/laporan-risetkesehatan-dasar-riskesdas/

Kementerian Kesehatan. (2020). STBM Review 2018: Data, Temuan dan Rekomendasi. http://stbm.kemkes.go.id/review_stbm/findings.html

Musfirah, M., Damayanti, G. R., Wardani, N. O., Putri, M. Z. C., Savitri, S., Salsabila, A. N., \& Basyaroh, A. P. A. (2020). Pemicuan STBM Pilar CTPS Pada Masyarakat Di 
Dusun Pringgolayan. Jurnal Pemberdayaan: Publikasi Hasil Pengabdian Kepada Masyarakat, 4(2), 211-218. https://doi.org/10.12928/jp.v4i2.1965

Muslikah, M., Ganefati, S. P., \& Purwanto, P. (2014). Hubungan Penerapan Sanitasi Total Berbasis Masyarakat (STBM) dengan Perilaku BAB dan CTPS Masyarakat Desa Caturharjo, Sleman, Yogyakarta Tahun 2013. Sanitasi: Jurnal Kesehatan Lingkungan, 5(4), 177-184.

Musyoki, S. M. (2016). Roles and responsibilities for post-ODF engagement: Building an enabling institutional environment for CLTS sustainability. Sustainable Sanitation for All: Experiences, Challenges, and Innovations, 167.

Peal, A., Evans, B., Ahilan, S., Ban, R., Blackett, I., Hawkins, P., Schoebitz, L., Scott, R., Sleigh, A., Strande, L., \& Veses, O. (2020). Estimating Safely Managed Sanitation in Urban Areas; Lessons Learned From a Global Implementation of Excreta-Flow Diagrams. Frontiers in Environmental Science, 8. https://doi.org/10.3389/fenvs.2020.00001

Prayitno, J., \& Widati, S. (2018). Kajian Strategi Promosi Kesehatan Sanitasi Total Berbasis Masyarakat (Stbm) Di Kelurahan Kejawan Putih Tambak Kota Surabaya. Jurnal Kesehatan Lingkungan, 10(3), 267-275.

Qasim, S. R., \& Chiang, W. (1994). Sanitary landfill leachate: Generation, control and treatment.

Rasako, H. (2018). Perilaku Peserta Sebelum dan Sesudah Pemicuan Sanitasi Total Berbasis Masyarakat di Wilayah Kerja Puskesmas Kairatu Kabupaten Seram Bagian Barat. GLOBAL HEALTH SCIENCE (GHS), 3(1), 96-102. https://doi.org/10.33846/ghs.v3i1.295

Sanan, D., \& Moulik, S. G. (2007). Community-led total sanitation in rural areas: An approach that works. New Delhi, India: Water and Sanitation Program-South Asia, The World Bank, 12.

World Health Organization. (1981). Drinking-water and sanitation, 1981-1990: A way to health, a WHO contribution to the International Drinking Water Supply and Sanitation Decade. World Health Organization.

Zuin, V., Delaire, C., Peletz, R., Cock-Esteb, A., Khush, R., \& Albert, J. (2019). Policy Diffusion in the Rural Sanitation Sector: Lessons from Community-Led Total Sanitation (CLTS). World Development, 124, 104643. https://doi.org/10.1016/j.worlddev.2019.104643 